\title{
EFEITO DA AVALIAÇÃO DA VACINAÇÃO ANTIRRÁBICA E SUPLEMENTAÇÃO COM DIFERENTES DOSES DO PROBIÓTICO NA RESPOSTA IMUNE HUMORAL EM BEZERROS NELORE.
}

\author{
Suelen Navas Ubida ${ }^{1}$, Paulo Eduardo Pardo ${ }^{2}$ \\ ${ }^{1}$ Mestre em Ciência Animal pela Universidade do Oeste Paulista - UNOESTE, Presidente Prudente - SP. ${ }^{2}$ Doutor em \\ Medicina Veterinária pela Universidade Estadual Paulista Júlio de Mesquita Filho (UNESP), SP, Brasil. E-mail: \\ suellen ubida@hotmail.com.br.
}

\section{RESUMO}

Quarenta e dois bovinos machos, Puro de Origem (P.O) da raça Nelore, com idade de 12 meses, todos vacinados com dose única de vacina antirrábica, divididos aleatoriamente em 3 grupos (14 bovinos/grupo): 0 grupo controle (GC), recebeu 70 gramas de suplemento mineral/animal por 60 dias; o grupo GP3 recebeu 3 gramas de probiótico adicionados em 70 gramas de suplemento mineral/animal por 60 dias e o grupo GP8 recebeu 8 gramas de probiótico adicionado em 70 gramas de suplemento mineral/animal por 60 dias. Análises estatísticas foram comparadas entre os Grupos controle, 3 e 8 gramas. As amostras de sangue dos bovinos foram colhidas nos dias 0,30 e 60 . Os resultados demonstraram diferenças estatísticas significativas entre as médias de concentrações séricas entre os grupos. Conclui-se que a administração de probiótico aumentou a resposta imune em bovinos vacinados com uma única dose de vacina antirrábica.

Palavras-chave: Raiva. Probiótico. Bovino. Resposta Imune.

\section{EFFECT EVALUATION OF ANTIRRABIES VACCINATION AND SUPPLEMENTATION WITH DIFFERENT DOSES OF PROBIOTIC IN THE HUMORAL IMMUNE RESPONSE IN NELORE CALVES.}

\begin{abstract}
Forty-two male animals, whole, Pure Origin (PO) Nellore, aged 12 months, all vaccinated with a single dose of rabies vaccines were randomly divided into 3 groups (14 bovine animals/group): Control group $(\mathrm{GC})$ received 70 grams of mineral/animal durig 60 days supplement; the probiotic group GP3 received 3 grams of probiotic added 70 grams of mineral/animal durig 60 days supplement; the probiotic group GP8 received 8 grams of probiotic added 70 grams of mineral/animal durig 60 days supplement. Statistical analyzes were compared between groups control, 3 , and 8 grams. Blood samples of animals were

collected days 0,30 and 60 days. Individual neutralizing antibody titers were determined by a neutralization technique based on the Rapid Fluorescent Focus Inhibition Test (RFFIT) and Fluorescent Inhibitio Microtest (FIMT). There were statistically significant differences between the mean serum concentrations between groups control, GP3 and GP8. Concluding that the administration of probiotics interfered in the humoral immune response.

Keywords: Rabies, Probiotic, Cattle, Immune Response.
\end{abstract}

\section{INTRODUÇÃO}

A raiva é uma enfermidade infecciosa viral do sistema nervoso central dos mamíferos, 
causada por um vírus neurotrópico, RNA, de ordem Mononegavirales, família Rhabdoviridae e do gênero Lyssavirus (REIS et al., 2013), onde no Brasil, o principal agente transmissor do vírus rábico é o morcego hematófago Desmodus rotundus (ALBAS et al., 2006; SCHEFFER et al., 2007).

A vacinação de bovinos contínua e periódica é a melhor forma de proteger e controlar a doença, porque a vacinação é de baixo custo eficaz e reduz perdas econômicas (REIS et al., 2013).

Para que haja um estado imunitário suficiente para proteger indivíduos expostos ao risco de infecção, a Organização Mundial de Saúde recomenda como parâmetro de imunidade antirrábica títulos protetores de anticorpos iguais ou maiores que 0,5 $\mathrm{Ul} / \mathrm{ml}$ (Unidade Internacional UI/ml (CHABEL et al., 2009; OMS, 2011).

Uma das estratégias para aumentar a resposta imunológica dos animais à imunidade induzida ou às infecções provocadas por vírus ou bactérias é o acréscimo de probióticos ao suplemento mineral utilizado (ARENAS et al., 2009; FERREIRA et al., 2009, PENHA et al., 2011).

Os probióticos são definidos como adjuntos dietéticos microbianos que afetam beneficamente a fisiologia do hospedeiro pela regulação da imunidade local e sistêmica e pela melhora do balanço nutricional e microbiano no trato intestinal (COOK et al., 2012). Dentre os efeitos benéficos dos probióticos, estão sua utilização como promotores de crescimento aumentando o ganho de peso, a redução do pH intraluminal do tubo digestivo, minimizando o estresse, impedindo a colonização da mucosa intestinal por bactérias patogênicas e aumentando a resposta imune humoral (PENHA et al., 2011; ALMEIDA et al., 2013).

Objetivou-se avaliar os efeitos da suplementação do probiótico em diferentes doses, sobre a resposta imune humoral em bovinos vacinados com uma única dose da vacina antirrábica.

\section{MATERIAL E MÉTODOS}

O experimento foi desenvolvido nos meses de setembro a novembro de 2013, no município de Pirapozinho, localizado a oeste o Estado de São Paulo, Brasil, cuja latitude $22^{\circ} 16^{\prime} 31^{\prime \prime}$ sul e longitude $51^{\circ} 30^{\prime} 00^{\prime \prime}$ oeste, estando a uma altitude de 487 metros, com precipitação anual média de aproximadamente de $1.300 \mathrm{~mm}$, umidade relativa do ar de aproximadamente 65,5\% (chuvas em todas as estações do ano), temperatura média de $23,5^{\circ} \mathrm{C}$. Utilizaram-se 42 bovinos, machos inteiros, Puro de Origem (P.O), da raça Nelore, com 12 meses de idade, todos vacinados com dose única de vacina antirrábica, divididos aleatoriamente em 3 grupos (14 bovinos/grupo), onde o grupo controle $(\mathrm{GC})$ recebeu 70 gramas de suplemento mineral/animal por 60 dias. 0 grupo GP3, recebeu 3 gramas de probiótico adicionado em 70 gramas de suplemento 
mineral/animal por 60 dias e o grupo GP8, recebeu 8 gramas de probiótico adicionado em 70 gramas de suplemento mineral/animal por 60 dias.

As amostras de sangue dos bovinos foram colhidas nos dias 0, 30 e 60. Os bovinos foram levados no período da manhã para o curral, contidos em tronco de contenção tipo Brete e $10 \mathrm{ml}$ de sangue de cada animal foi colhido por meio da punção da veia jugular em tubos à vácuo sem anticoagulante. Os tubos foram transportados em caixa térmica com gelo e após cerca de 2 horas foram centrifugados a $2.500 \mathrm{rpm}$ por 10 minutos. As amostras de soro foram acondicionadas em tubos plásticos de 1,5 mL e armazenadas em freezer a -20 ำ para posterior determinação do título de anticorpos neutralizantes antirrábicos.

Os títulos de anticorpos neutralizantes antirrábicos foram determinados no Laboratório de Raiva do Instituto Butantã - São Paulo, por meio da técnica de soroneutralização em células BHK21, teste esse, baseado no Rapid Fluorescent Focus Inhibition Test - RFFIT (SMITH et al., 1998) e no Fluorescent Inhibition Microtest - FIMT (ZALAN et al., 1979).

Os bovinos foram alimentados com capim Tanzânia em sistema de pastejo extensivo e os piquetes utilizados pelos grupos de animais serão semelhantes na topografia e composição botânica, sendo formados por Podzolizados de Lins - variedade Marília (arenoso) menor áreas, Latossol Vermelho Escuro fase arenosa (maior área), Campos e Cerrados e Latossol Roxo - terra roxa (pequena área), margeando o Rio Paranapanema. Todos os piquetes possuíam pasto abundante e sombra. O sistema de pastejo adotado foi o extensivo.

O probiótico comercial utilizado foi Proenzime ${ }^{\circledR}$ - produzido por Empresa Brasileira de Aumento de Produtividade Pecuária - EMBRAUPEC, Paranavaí - PR, Brasil, devidamente registrado e aprovado pelo Ministério da Agricultura, Pecuária e Abastecimento (MAPA).

Utilizou-se o suplemento mineral Fosbovi Seca ${ }^{\circledR}$ da linha bovinos, produzida por Tortuga Companhia Zootécnica Agrária, São Paulo, SP.

Utilizou-se a vacina antirrábica (Vencofarma) contendo vírus fixo Pasteur inativado, adsorvido em gel de hidróxido de alumínio produzido em cultivo celular. A aplicação foi feita no dia zero do experimento em todos os bovinos numa dose de $2 \mathrm{~mL}$ de vacina por via subcutânea.

\section{ANÁLISE ESTATÍSTICA}

Previamente às comparações estatísticas, o pressuposto de normalidade dos dados foi avaliado individualmente para cada grupo de variáveis pelo teste de Shapiro-Wilk para verificar se os dados observados apresentaram distribuição gaussiana, pelo qual constatou-se que as variáveis estudadas apresentaram distribuição não paramétricas ( $P \leq 0,05)$. A comparação dos 
títulos sorológicos entre os grupos controle e tratado, aos 30 e aos 60 dias, foi realizada pelo teste de Kruskall-Wallis, com contrastes pelo método de Dunn. Os títulos sorológicos dentro de cada grupo, aos 30 e aos 60 dias pós-vacinação, foram comparados pelo teste de Wilcoxon para amostras relacionadas (PAGANO \& GAUVREAU, 2004).

Foram considerados títulos protetores contra raiva, animais que apresentaram $\geq 0,5$ unidade soroneutralizante. Desta forma, os percentuais de animais protegidos contra raiva, dentro de cada momento, foram comparados pelo teste de qui-quadrado com contrastes pelo método de partição. Para determinar se o percentual de animais protegidos diferiu entre momentos dentro de cada grupo recorreu-se ao teste exato de Fisher. Todas as análises foram realizadas com auxílio do pacote computacional Bioestat v.1.0 (AYRES et al., 2007) adotando-se como nível de significância o valor de 5\%.

\section{RESULTADOS E DISCUSSÃO}

No dia zero, os soros dos animais não apresentaram anticorpos neutralizantes para a raiva, demonstrando que os bovinos não tiveram contato com o vírus rábico selvagem ou vacinal. Assim, as variações encontradas nos títulos de anticorpos antirrábicos nos soros desses animais durante o experimento foram induzidas pela administração da vacina e do probiótico.

Tabela 1. Média aritmética, Mediana e intervalo interquartil (IQ) de títulos sorológicos em unidades soroneutralizantes mensurados pela técnica de RIFF em três grupos experimentais vacinados contra raiva com vírus rábico vacinal cepa vírus Pasteur, Presidente Prudente, 2014.

\begin{tabular}{|c|c|c|c|c|c|c|}
\hline \multirow[t]{2}{*}{ Grupo } & 30 dias & \multirow[b]{2}{*}{ Mediana } & & \multirow[b]{2}{*}{ Média } & \multirow[b]{2}{*}{ ? d.p. } & \multirow{2}{*}{$\begin{array}{l}60 \text { dias } \\
\text { Mediana }\end{array}$} \\
\hline & $\begin{array}{l}\text { Média ol d.p. } \\
\text { IQ }\end{array}$ & & & & & \\
\hline Controle & 0,052 回 0,006 (Aa) & 0,050 & 0,000 & 0,050 ? 0,000 (Aa) & 0,050 & 0,000 \\
\hline 3 Gramas & 0,685 ? 0,502 (Ba) & 0,495 & 0,715 & 0,451 0,325 (Ba) & 0,330 & 0,468 \\
\hline 8 Gramas & 3,061 目 2,977 (Ba) & 1,670 & 2,805 & 2,744 ? 2,960 (Ca) & 1,020 & 3,600 \\
\hline
\end{tabular}

d.p. - Desvio padrão. Letras maiúsculas diferentes na mesma coluna ou letras minúsculas diferentes na mesma linha indicam diferenças estatísticas significativas.

$\mathrm{Na}$ Tabela 1 foram observadas diferenças estatísticas significativas entre os grupos avaliados 30 e 60 dias pós-vacinação, demonstrando que o GC não estava protegido durante todo o experimento, pois não apresentaram títulos considerados protetores $(P \geq 0,50 \mathrm{UI} / \mathrm{mL})$. Os grupos GP3 e GP8, respectivamente 30 e 60 dias após a imunização antirrábica dos bovinos, 
apresentaram médias de títulos de anticorpos antirrábicos significativamente maiores que o grupo GC e essas médias estavam acima do título considerado protetor $(P \geq 0,50 \mathrm{UI} / \mathrm{mL}$ ). $O$ grupo GP3 aos 30 dias apresentou títulos de anticorpos protetores mínimos ( $P \geq 0,50 \mathrm{UI} / \mathrm{mL})$ e aos 60 dias o grupo GP3 não apresentou títulos de anticorpos protetores. O GP8 aos 30 e 60 dias, apresentou uma maior concentração de títulos de anticorpos comparados ao GC e GP3 demonstrando ser mais eficiente comparado ao GC e GP3.

Os resultados obtidos concordam o trabalho de Arenas et al. (2009), que observaram aumento significativo ( $\mathrm{P} \leq 0,05 \mathrm{UI} / \mathrm{ml}$ ) nos títulos de anticorpos antirrábicos nos bovinos suplementados com 0, 2, 3, 4 e 8 gramas do probiótico Proenzime ${ }^{\circledR}$ para bovinos primovacinados contra a raiva.

Essa elevação dos títulos de anticorpos pelo grupo GP8 deve-se ao efeito do estímulo ao sistema imunológico (REYES \& RODRIGUES, 2010; NOGUEIRA \& GONÇALVES, 2011).

A ação imunoestimulante dos probióticos é atribuída às bactérias ácido láticas, dentre as quais Lactobacilus acidophilus, Bifidobacterium bifidum e Bifidobacterium longum (ALMEIDA et al, 2012).

Nogueira e Gonçalves (2011) mostraram que os probióticos estimulam a atividade fagocítica dos leucócitos, aumentam a proliferação de linfócitos T e a atividade dos macrófagos, elevam a atividade das células Natural Killer (NK); ativam as células T Helper CD4+ subpopulação Th1. Com o uso de probióticos bactérias da microflora intestinal e células Th3, atuam no balanço Th1/Th2, promovendo o controle de processos infecciosos e imunológicos (COSTA \& VARAVALLO, 2011).

Os probióticos aumentam a produção de anticorpos e a secreção de mediadores químicos como, citocinas, interferon gama (IFN-?]), fator de necrose tumoral (TNF), interleucina (IL) 1 e 2, que estimulam o sistema imunológico (PARDO \& REIS, 2008).

A figura 1 compara os títulos soroneutralizantes mensurados aos 30 e 60 dias pósvacinação, direcionados contra o vírus rábico vacinal cepa vírus Pasteur para bovinos do grupo GC, GP3 e GP8. 


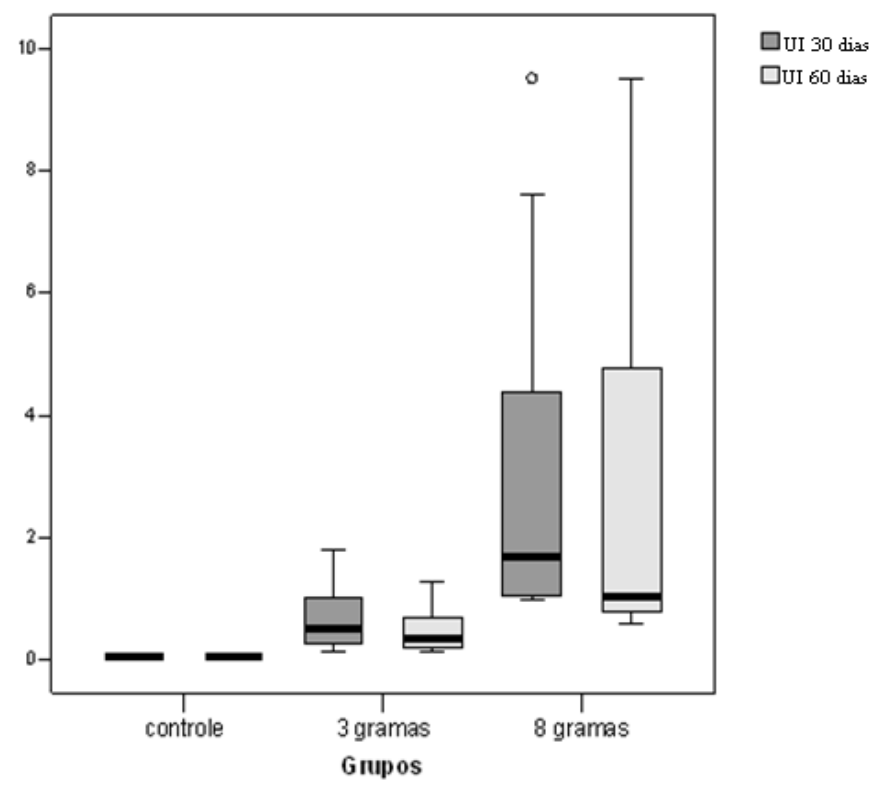

Figura 1. Títulos soroneutralizantes mensurados aos 30 e 60 dias pós-vacinação com vírus rábico vacinal cepa vírus Pasteur para bovinos do grupo controle, grupo suplementado com 3 gramas de probiótico e grupo suplementado com 8 gramas de probiótico. As linhas no interior dos boxes denotam o segundo quartil ( $50 \%$ dos dados - mediana), as linhas superiores, o terceiro quartil ( $75 \%$ dos dados) e as inferiores o primeiro quartil ( $25 \%$ dos dados). As linhas aplicadas indicam os limites dos valores extremos.

Tabela 2. Percentual de animais protegidos contra raiva mensurados aos 30 e 60 dias pós vacinação em três grupos submetidos a diferentes tratamentos, Presidente Prudente, 2014.

\begin{tabular}{ccccccc}
\hline \multirow{2}{*}{ Grupo } & \multicolumn{3}{c}{30 dias } & \multicolumn{3}{c}{60 dias } \\
\cline { 2 - 6 } & Protegidos & Não protegidos & Total & Protegidos & $\begin{array}{c}\text { Não } \\
\text { protegidos }\end{array}$ & Total \\
\hline Controle & $0(0 \%)$ & $14(100 \%)$ & $14(100 \%)$ & $0(0 \%)$ & $14(100 \%)$ & $14(100 \%)$ \\
3 gramas & $7(50 \%)$ & $7(50 \%)$ & $14(100 \%)$ & $6(42,8 \%)$ & $8(57,2 \%)$ & $14(100 \%)$ \\
8 gramas & $14(100 \%)$ & $0(0 \%)$ & $14(100 \%)$ & $14(100 \%)$ & $0(0 \%)$ & $14(100 \%)$ \\
\hline
\end{tabular}

Na Tabela 2 não foram observadas diferenças estatísticas significativas entre os títulos sorológicos nos três grupos experimentais aos 30 e 60 dias pós-vacinação antirrábica, dentro de cada grupo, quando avaliados pelo teste exato de Fisher $(P \geq 0,50 \mathrm{UI} / \mathrm{mL})$. No grupo $G C$, os animais do grupo em estudo não obtiveram proteção contra raiva (100\%) aos 30 e 60 dias do experimento, possivelmente porque o GC não possuía nenhum suplemento nutricional ligado ao estímulo do sistema imunológico e os bovinos não receberam aplicação da dose de reforço após 30 dias, concordando com estudos realizados por Rosa et al. (2013), que avaliaram a resposta imune humoral em bovinos vacinados com a antirrábica e suplementados com probiótico. No 
grupo GP3 aos 30 dias, 50\% dos animais encontram-se protegidos contra o vírus rábico e aos 60 dias 57,2\% dos animais não estavam protegidos contra o vírus rábico. O grupo GP8 (30 e 60 dias), mostrou-se mais eficiente, apresentando $100 \%$ dos animais protegidos. Houve diferenças significativas na influência no uso de 8 gramas de probiótico para o aumento na resposta imune humoral dos bovinos primovacinados.

Entretanto, os resultados obtidos não concordam com Ferreira et al. (2009), Almeida et al. (2012) e de Rosa et al. (2013) onde avaliaram a resposta imune humoral utilizando vacina antirrábica e suplementação com probiótico, concluindo em seus experimentos que vacina antirrábica teve eficiência em produzir e manter soroconversão nos bovinos e a administração do probiótico não interferiu na resposta imune humoral.

\section{CONCLUSÃO}

De acordo com os resultados obtidos, conclui-se, que a suplementação com 8 gramas de probiótico adicionado ao suplemento mineral aumentou a resposta imune humoral em bovinos vacinados com uma dose de vacina antirrábica.

COMITÊ DE ÉTICA E BIOSSEGURANÇA - Comissão de Ética no Uso de Animais (CEUA) - aprovado em 04/09/2013 - protocolo 1623.

\section{REFERÊNCIAS}

ALBAS, A. et al. Interval between first dose and booster affected antibody production in cattle vaccinated against rabies. Journal of Venomous Animals and Toxins including Tropical Diseases, Botucatu, v. 12, n. 3, p. 476-486, 2006. Acessado em 15 nov. 2013. Online. Disponível em: http://www.scielo.br/pdf/jvatitd/v12n3/31234.pdf

ALMEIDA, L. E. et al. Efeito do probiótico na resposta imune humoral em bovinos. Colloquium Agrarie, v.8, n.1, p.26-35, jan-jun, 2012. Disponível em: <http://revistas.unoeste.br/revistas/ojs/index.php/ca/article/viewFile/536/696>. Acesso em: 20 out. 2013. doi: 10.5747/ca2012. v.08.nl.a076.

ALMEIDA, L. E. et al. Utilização de probióticos sobre o ganho de peso em bovinos da raça nelore. Colloquium Agrarie, v.9, n.1, p.25-30, jan-iun, 2013. Disponível em:<http:// revistas.unoeste.br/revistas/ojs/index.php/ca/article/viewFile/537/981>. Acesso em: 02 nov. 2013. doi: 10.5747/ca2013. v.09.nl.a086.

ARENAS, S.E. et al. Probiotic increase the antirabies humoral immune Response in bovine. Archivos de Zootecnia, v. 58, p.733-736, 2009. Acessado em 12 out. 2013. Online. Disponível em:htpp:// http://scielo.isciii.es/pdf/azoo/v58n224/art11.pdf 
AYRES, M. et al. BioEstat 5.0: Aplicações estatísticas nas áreas das ciências biológicas e médicas. Belén do Pará Sociedade Civil Mamirauá, CNPq , 2007. 364p.

CHABEL, J.C. et al. Efeito de um complexo homeopático "Homeostase Convert H" em ovinos sob condições de retrição alimentar. Brazilian Journal of Veterinary Research and Animal Science. São Paulo, v.46, n.5, p.412-423, 2009. Acessado em 10 out. 2013. Online Disponível em: http://www.revistausp.sibi.usp.br/scielo.phppid=s141395962009000500010script=sciarttext

COOK, M.T. et al. Microencapsulation of probiotics for gastrointestinal delivery. Journal of Controlled Release, v.162, p.56-67, 2012. Disponível em:<http://www.sciencedirect.com/ science/article/pii/S0168365912004968>. Acessado em 02 out. 2013. doi: 10.1016/j.jconrel.2012.06.003.

COSTA, E.S.; VARAVALLO, M.A. Probióticos e prebióticos: relações com a imunidade e promoção da saúde. Revista Científica do ITPAC, v.4, n.2, abr, 2011. Acessado em: 25 fev. 2014. Online. Disponível em: http://www.itpac.br/Revista/42/6.pdf

FERREIRA, L.A. et al. Avaliação da vacinação anti-rábica e da suplementação com probiótico na resposta imune humoral em bovinos. Semina: Ciências Agrárias, Londrina, v. 30, n. 3, p. 655-660, jul-set, 2009. Acessado em: 01 set.2013. Online. Disponível em: htpp://www.uel.br/revistas/uel/index.php/semagrarias/article/download/3574/2885

Dissertação (Mestrado Ciência Animal) - Curso e Pós-graduação em Ciência Animal, Universidade do Oeste Paulista de Presidente Prudente.

NOGUEIRA, J.C.R.; GONÇALVES, M.C.R. Probiotics in allergic rhinitis. 2011. Revista Brasileira de Ciências da Saúde. v.15,n.4, p.487-792, 2011. Disponível em: http://www.biblionline.ufpb.br/ojs/index.php/rbcs/article/view/8201/6858. Acesso em 5 set. 2013. doi 10.4034/RBCS.2011.15.04.16

OMS. Rabies. World Health Organization, set. 2011. Acessado em 15 dez. 2013. Disponível em: http://www.who.int/mediacentre/factsheets/fs099/en/

PAgANo, M., GAUVReAU, K. Princípios de bioestatística. 2 ed. São Paulo: Pioneira Thomson Learneing, 2004. 506p.

PARDO, P.E.; REIS, L.S.L.S. Nutrientes e nutracêuticos em grandes animais. In: ANDRADE, S.F. Manual de terapêutica veterinária. 3.ed. São Paulo: Rocha Ltda., 2008. Cap. 29, p.808-814.

PENHA, L. A. C., et al. Effects of probiotic supplementation on liveweight gain and serum cortisol concentration in cattle. Veterinary Record, v.168, p.538, 2011. Acesso em 19 ago. 2013. Disponível em: http://dx.doi.org/10.1136/vr.d589

REIS, L.S.L.S., et al. Effects of primovaccination and booster vaccination on serum cortisol and humoral immune response in cattle. Advances in Bioscience and Biotechnology v.4, p.607-611, 2013. Disponível em: http://file.script.org/HI/1-7300550 31904.htm. doi:10.4236/abb.2013.45079

REYES; E.J.A; RODRIGUES;F.L. ?Qué sabe Ud. acerca de... los probióticos?. Revista Mexicana de Ciencias Farmacêuticas, México, v.41, n.1, p.60-3, 2010. Acessado em: 26 set.2013. Online. 
ROSA, E.R., et al. Avaliação da resposta imune humoral em bovinos vacinados com a antirrábica e suplementados com probiótico. Revista Científica Eletrônica de Medicina Veterinária, n.20, 2013. Acessado em 17 ago. 2013. Online. Disponível em: http://www.revista.inf.br

SHEFFER, K. C. et al. Vírus da raiva em quirópteros naturalmente infectados no Estado de São Paulo, Brasil. Revista de Saúde Pública, v. 41, n.3, p. 389-395, 2007. Acessado em 26 set. 2013. Online. Disponível em: htpp://www.scielo.br.pdf/rsp/v41n3/5872.pdf

SMITH, J,S. et al. A rapid luorescent focus inhibition test (RFFIT) for determing rabies virus-neutralizing antibody. In: MESTIN, F.X.; KAPLAN, M. M.; KOPROWSKI, H. (Ed). Laboratory techniques in rabies. Geneva: World Health Organization, 1998. p. 181-192.

ZALAN, E. et al. A microtest for the quantitation of rabies virus neutralizing antibodies. Journal of Biological Standardization, Saskatchewan, v.7, n.3,p.213-220,1979. Acessado em 25 set. 2013. Online. Disponível em: htpp://www.sciencedirect.com/science/journal/00921157/7 